removal of her furniture to another house; and, according to her husband's account, being a somewhat delicate woman, it was thought that the exertion consequent on their removal had induced this attack. She was not then in a condition to excite any serious apprehensions. Her pulse was good in volume, somewhat accelerated; the abdomen was slightly tender on pressure; and the pain she described as being inter. mitting arid very severe. She had also occasional vomiting. On inquiry, I found she had not menstruated for nine weeks. The treatment consisted in the exhibition of opium with small doses of calomel; a mixture containing hydrocyanic acid; and hot fomentations to the body.

When seen by my father, about eleven o'clock on the following morning, she said she was decidedly better; the pain was considerably relieved; but sickness had continued at intervals during the night. The pulse continued tolerably good; and she expressed an opinion that if she had something to allay the sickness, she could be removed in a cab. Shortly before two o'clock, her husband came down in great haste, to say that she had been taken much worse about an hour previously, and her friends thought she was dying. On my arrival, I found that it was so. The sickness had ceased, and the pain become greatly aggravated about twelve o'clock; she was alarmingly faint; her extremities were cold; her pulse scarcely perceptible; and though brandy and other stimulants were freely administered, she died in about an hour after my arrival. The impression on our minds was, that she had died from perforation of the stomach or bowel.

A post-mortem examination was made the following day. On opening the abdomen, several pounds of extravasated blood were found in the cavity of the peritoneum, an immense clot filling the pelvis and extending into the abdomen on the right side. The stomach and bowels were distended with flatus and healthy. After removing the clots, the uterus and appendages were examined, when the cause of the hæmorrhage became at once apparent, viz., the existence of extrauterine fœtation in the right Fallopian tube. The cyst had been developed in the tube close to the fimbriated extremity, which was dilated suffi. ciently to allow the passage of the end of the little finger, and plugged with coagulum. A rent existed in the cyst just within the tube, and the membranes entire, with a small fotus floating in them, still remained in the cyst, surrounded with coagulated blood. The uterus was considerably larger than in the usual unimpregnated condition. The other organs were healthy, with the exception of the right kidney, which had undergone thorough scrofulous degeneration, consisting of nothing but cavities filled with scrofulous pus, the substance of the organ having been totally destroyed. The ureter was large and thickened, and was blocked up in its whole length with cheesy matter.

REmarks. This case is one of great interest, not only on account of the rare occurrence of the mischief which caused death, but as illustrating how serious an amount of local dis. ease may exist, with very trifling constitutional disturbance; for so little had she suffered from the disorganisation that was going on in the kidney, that (though, as her husband expressed it, " being somewhat delicate") she had been in the enjoyment of what she considered good health, and never had any symptoms which made it necessary to consult her usual medical attendant.

\section{SPONTANEOUS EVOLUTION IN A CASE OF ARM PRESENTATION.}

By Chardes Young, Esq., Surgeon, Chilton Polden.

THE following case illustrates the opinion of Denman and others, that the change in position which occasionally takes place in presentations of the upper extremity, by means of which the child is expelled without manual interference, and which is termed "spontaneous evolution", is in reality a doubling and expulsion produced by the continuance of uterine contractions.

CASE. About three weeks previously to her confinement, Mrs. H., aged 30 , pregnant with her second child, received an accidental blow in the abdomen by falling against a chair. This caused considerable pain; she did not afterwards perceive the movements of the child in utero, and felt a coldness and weight in the abdomen.

I was first called to visit her at 11 A.M. on the 4th instant. She had then been in pain for three hours; and the waters were discharged, together with a little dark coloured blood, a few minutes previous to my arrival. The pains were very feeble; and, on examination, I found that the os uteri would scarcely admit the point of my finger, and was high up towards the promontory of the sacrum. Concluding from these circum. stances that the labour would be a protracted one, I left her, and directed the nurse to send for me when the pains became strong and regular.

I was not summoned until 6 A.sr. the following morning. The uterus was then acting powerfully; the passages were thoroughly dilated; and the child's arm was in the vagina; and, directly afterwards, the hand itself protruded from the os externum, and its flaccid feel indicated that the child was dead. With the hope of quieting the action of the uterus, which rendered turning impossible, I gave forty minims of tincture of opium. The pains, nevertheless, continued; the child gradually descended; and, in about three-quarters of an hour, the breech and one arm were expelled together, and the remainder of the body followed without difficulty.

I may remark, that the child was not quite mature; its death was, in all probability, caused by the fall which my patient suffered three weeks before her confinement, and perhaps from separation of the placenta: hence the dark coloured blood which accompanied the liquor amnii, although no hæmorrhage appeared externally at the time of the accident. Labour occurred about ten days before the expiration of the ninth month ; consequently, the child was at the eighth month of gestation at the time of its death. Being immature, and decomposition having begun, it was doubtless expelled more readily than a full grown and living foetus would have been; but the mechanism of its expulsion would be similar, although in the great majority of such cases, delivery is not to be looked or hoped for without the operation of turning, and that, if possible, before the membranes have been ruptured spontaneously.

\section{ON THE MORTALITY OF INFANTS IN FOUND- LING INSTITUTIONS, AND GENERALLY, AS INFLUENCED BY THE ABSENCE DF BREAST-MILK.}

By C. H. F. Routh, M.D., Physician to the Samaritan Free Hospital for Women and Children ; late Physician to the St. Pancras Royal Dispensary; etc.

Part II.

[Continued from page 105.]

Physical Qualifications. The physical qualifications of a wet nurse may be summed up under the following heads :-

1. That she has good milk.

2. Hereditary predisposition good.

3. Age not to exceed 30 .

4. She should not have been confined many months before the child's mother.

5 . She should be of the melancholic temperament.

6. She should have not only good quality, but a sufficient quantity of milk.

7. When a wet nurse cannot be given to a child exclusively, a married woman suckling another child may be employed as an adjuvant.

1. She should have good milk. This point is best treated in the consideration of what are the characters of good human milk. One of the best evidences of a wet nurse's good physical constitution, is the secretion of an abundance of healthy and nutritious milk. Good human milk has an average specific gravity of 1032 , varying from 1030 to 1034 . It is always strongly alkaline; this alkalinity it usually retains from five to six days, when it becomes acid. To the taste it is sweet, much more so than cow's milk. When allowed to stand, it will be seen to separate into two portions. The superficial very white substance, known familiarly as cream, is nothing else than the oil-globules which, being of a lower specific gravity than the other portions of the milk, rise to the surface. The more transparent subjacent liquid is the casein, sugar, and milk. The agitation of the cream breaks asunder the oilglobules, which in this state constitute butter. If the milk, after the cream has separated from it, be kept any time, the sugar contained in it becomes converted into lactic acid, which gradually precipitates the casein as a curd. Rennet, or the mucous membrane of the stomach, and most acids, have the same effect. The fluid which now remains, technically called whey, contains, still in solution, $a$ large quantity of sugar and he salts of milk, which are readily separated by evaporation. 